\title{
Sintered transparent polycrystalline ceramics: the next generation of fillers for clarity enhancement in corundum
}

\author{
Mubashir Mansoor ${ }^{\text {a,b, }, \text {, Mehya Mansoor }}{ }^{\text {a,c }}$, Maryam Mansoor ${ }^{\text {a,d }}$, Ted Themelis ${ }^{\text {e }}$, \\ Filiz Çinar Şahin ${ }^{a}$ \\ ${ }^{a}$ Department of Metallurgical and Materials Engineering, Istanbul Technical University, Maslak 34467, Istanbul, Turkey \\ ${ }^{b}$ Department of Applied Physics, Istanbul Technical University, Maslak 34467, Istanbul, Turkey \\ ${ }^{c}$ Department of Geological Engineering, Istanbul Technical University, Maslak 34467, Istanbul, Turkey \\ ${ }^{d}$ Department of Mining Engineering, Istanbul Technical University, Maslak 34467, Istanbul, Turkey \\ ${ }^{e}$ GemLab, Bangkok 10120, Thailand
}

\section{A B S T R A C T}

A significant proportion of mined natural corundum (ruby and sapphire) contain fractures, which negatively affect a gemstone's clarity and value. Over the past decades, heat treatment techniques have been developed for either fracture healing or filling to make such gems marketable. The clarity enhancement processes are mainly based on techniques which are either not durable, as in the case of lead silicate fillers, or do not yield perfect transmittance through a fracture, as in the case of borax based fluxes. Therefore, the gemstone treatment community is actively in pursuit of better techniques for clarity enhancement in corundum. Given that application of pressure is a recent advancement in the heat treatment processes of natural sapphire, it is essential to explore the possibilities regarding different outcomes such treatments can have. In this perspective paper, we have briefly described how the application of pressure during heat treatments can lead to in-situ sintering of transparent polycrystalline ceramics within the fractures of corundum, which can result in clarity enhancement. Spinelstructure based fillers can be tailored to mimic corundum in terms of tribological, chemical, and optical properties. Therefore, gemstones treated with such fillers will be durable, unlike currently used glass-based filler material. We also provide a possible explanation for ghostfissures in sapphires heated under pressure, as being a by-product of an in-situ sintering process of ceramic fillers that are thermodynamically compatible with $\mathrm{Al}_{2} \mathrm{O}_{3}$. The prospect of transparent polycrystalline ceramics in the gem and jewelry industry opens a new field of research in this area, given that ceramic fillers can outperform currently used methods and materials for clarity enhancement in gemstones. In essence, we present a novel application for sintered transparent polycrystalline ceramics.

(C) 2021 The Authors. Published by Synsint Research Group.

\section{KEYWORDS}

\author{
Transparent ceramics \\ Heat treatment \\ Sapphire \\ Transient liquid phase sintering \\ High temperature + pressure $(\mathrm{HT}+\mathrm{P})$ \\ High pressure high temperature (HPHT)
}

Single crystal alpha-alumina $\left(\alpha-\mathrm{Al}_{2} \mathrm{O}_{3}\right)$, or corundum is generally known as ruby if red, and sapphire in case of all other colors.
Corundum is widely used for technological and industrial applications, including optoelectronic devices such as lasers and LEDs, optical

\footnotetext{
* Corresponding author. E-mail address: mansoor17@itu.edu.tr (M.Mansoor)

Received 16 August 2021; Received in revised form 28 September 2021; Accepted 29 September 2021.

Peer review under responsibility of Synsint Research Group. This is an open access article under the CC BY license (https://creativecommons.org/licenses/by/4.0/). https://doi.org/10.53063/synsint.2021.1342
} 
windows, and ballistic armors. The wide electronic band gap of sapphire makes it highly transparent in 200 to $4000 \mathrm{~nm}$ range, and therefore it is colorless in the absence of significant intrinsic and extrinsic defects. The $20 \mathrm{GPa}$ Vickers hardness of sapphire, melting temperature of $2050{ }^{\circ} \mathrm{C}$, chemical inertness to corrosive media (acidic or high-temperature), and wide transparency range have made it possible to use $\mathrm{Al}_{2} \mathrm{O}_{3}$ for demanding applications [1]. However, one of the oldest applications of this material can be seen in the jewelry industry, as a gemstone. Major deposits of natural corundum are found and mined in Sri Lanka, Myanmar, Tanzania, Kenya, Madagascar, Australia, and Mozambique just to name a few. A comprehensive list of corundum deposits has been reported in the literature [2, 3]. Dopants and defect equilibria in corundum crystals are primarily responsible for the wide range of colors. Transition metal dopants with d-shell contribution to the density of states can cause deep levels in the electronic band gap, which can result in absorption within the visible spectrum. The influence of charged and acceptor defects on color are especially remarkable in corundum [4]. Hereafter, corundum, ruby and sapphire terms are used only when referring to single crystal $\mathrm{Al}_{2} \mathrm{O}_{3}$, and alumina refers to polycrystalline $\mathrm{Al}_{2} \mathrm{O}_{3}$.

The majority of natural corundum is heat treated, for modifying color and/or clarity [5-7]. Natural sapphires often contain secondary phases in their microstructure, which reduce clarity due to scattering of light [8]. Precipitates in a gemstone can be dissolved into the host crystal lattice at particular treatment conditions, as dictated by thermodynamic equilibria to produce a solid solution, thereby changing defect chemistry of such crystals, which can generally alter the color and/or increase clarity [6]. Rutile, hematite and ilmenite are often reported as nano or micron size precipitates in sapphire [6,8], dissolution of which can alter the overall color of a gemstone. In fact, dissolution of titanium oxide or sub-oxides in sapphire makes up a considerable proportion of commercially produced blue sapphires. Themelis [6], Nassau [9], and Emmett et al. [10] have explained this heat treatment process in detail. The purpose of some treatments is to decrease the impact of fractures on the clarity of a gemstone, which is achieved either by growing synthetic corundum in the fractures through fluxes (generally referred to as fracture healing), or by using fillers of similar refractive index as that of corundum $(1.76-1.77$ at $588 \mathrm{~nm})$ [7, 11]. Healing of fractures through fluxes, such as borax, takes places by dissolving alumina from the corundum surfaces, and forming a supersaturated solution, which leads to crystallization of synthetic corundum through slow cooling or evaporation. Fracture healing can cause a substantial increase in transmittance of light through a fracture, as shown in Fig. 1. However, considering the ternary phase diagram [12] of $\mathrm{Al}_{2} \mathrm{O}_{3}-\mathrm{B}_{2} \mathrm{O}_{3}-\mathrm{Na}_{2} \mathrm{O}$ for the case of borax as a flux, it can be seen that crystallization of boroaluminate and sodium aluminate phases are inevitable, causing a eutectic microstructure. Such aluminates have significantly different optical properties in comparison to corundum, and thus reduce the efficiency of this treatment. As part of the fracture healing method the induced eutectic, peritectic or eutectoid microstructures are an inherent part of the process, with corundum being one of the multiple phases solidifying upon cooling. Given that such microstructures are generally not comprised of phases of the same optical properties, the transmittance through a healed fracture is not optimal [13]. Themelis [7] and Emmett [11] have explained the fracture healing process in detail. It is noteworthy that such eutectic, eutectoid, or peritectic

\section{FRACTURE HEALING}

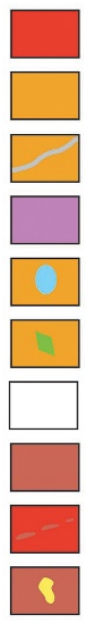

Host Corundum

Flux + Alumina

Eutectic Solidification

Heterogeneous Nucleation

Trapped Gas Bubble

Secondary Phases

Void

Eutectic Microstructure

Partially Healed Fissure

Crystals from Residual Fluid

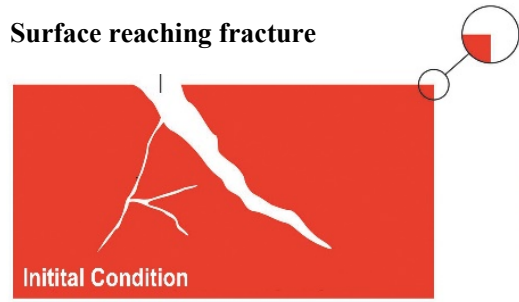

Recrystallized Surface
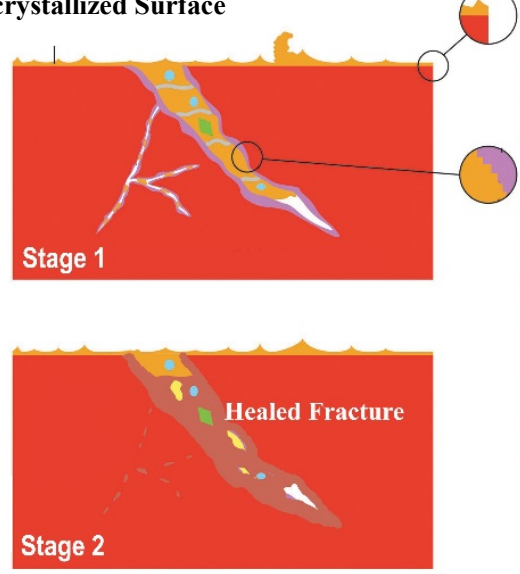

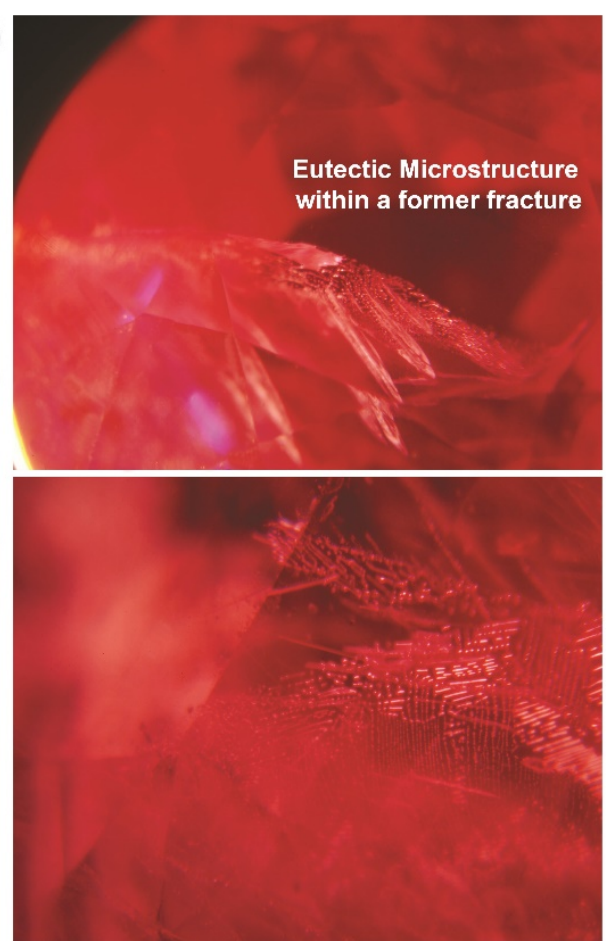

Fig. 1. Left: a schematic overview of the conventional fracture healing process, which uses fluxes. A surface reaching fissure or crack is filled with a fluxing agent, which dissolves alumina from the corundum surfaces and recrystallizes the corundum phase within fractures, followed by a eutectic solidification. Right: micrograph of a ruby treated in this manner, captured under an optical microscope. Fractures are now far more capable of transmitting light, but the secondary phases (or residues) tend to reduce the efficiency of the treatment process. (Photo Credit: Ted Themelis) [7]. 
microstructures are referred to as "fingerprint inclusions" [14] in the gemological literature. Fillers are not perfect either. Majority of the used formulations for a filler material, such as lead silicates, have significantly different tribological properties, while not being resistant to corrosive media, through which jewelry production takes place, resulting in a product that is not durable [15]. For in depth information regarding heat treatments of ruby and sapphire, interested researchers are referred to the comprehensive books on this topic $[6,7,16]$. Given the problems associated with present methods of clarity enhancement, the gemstone heat treatment community is actively in pursuit of better techniques, which makes it important to study the possibilities in this regard to safeguard the fine jewelry industry from treatments that may go undisclosed.

Application of pressure during heat treatment of natural sapphire is a recent development [17]. The method is primarily based on hot press technology, where sapphires are heated under a pressure of approximately $1 \mathrm{kbar}$ and temperatures of 1600 to $1800{ }^{\circ} \mathrm{C}$ [17-19]. Sapphire has a ductile brittle transition temperature of $1100{ }^{\circ} \mathrm{C}$ [20]. Therefore, plastic deformation and rapid diffusion through line defects are an inherent part of the process. Both of which are well documented at this pressure and temperatures [21-23]. This makes pressure assisted heat treatment of sapphire rather controversial and significantly different from previous heat treatment techniques. Moreover, these are conditions under which sintering of transparent polycrystalline ceramics can prevail [24]. Considering the suspicions over involvement of lithium compounds (i.e. lithium carbonate) in the process [18], we find it necessary to explore the potentials of transparent ceramics on the clarity enhancement of corundum. The following paragraphs briefly introduce transparent ceramics and describe how an in-situ sintering of a spinel phase can be achieved within the fractures of such gemstones, through the application of pressure in the treatment process.

Transparent ceramics have a long-range atomic order and are therefore crystalline material, unlike glasses. Many of the gemstones are transparent ceramics as well, such as; sapphire, emerald, quartz and many more. However, these gemstones are single crystals, unlike the polycrystalline nature of industrially sintered ceramics, which have the same chemical composition. Therefore, optical properties of transparent polycrystalline ceramics are either identical or extremely close to their single crystal counterparts, when it comes to indices of refraction, dispersion, density, melting point, coefficients of thermal expansion and so on $[1,24]$. Polycrystalline transparent ceramics are generally produced through sintering of the precursor powder under pressure, and serve a wide range of industries [25]. The most commonly used equipment for sintering of transparent ceramics are; hot-press (HP), hot isostatic press (HIP) and spark plasma sintering (SPS), as well as vacuum furnaces if the powder is compacted under pressure through cold isostatic pressing (CIP) [24]. Mao et al., [26] have shown that it is possible to produce transparent polycrystalline alumina with optical properties identical to that of sapphire by sintering $\mathrm{Al}_{2} \mathrm{O}_{3}$ powder at $1850{ }^{\circ} \mathrm{C}$ for 3 hours in hydrogen atmosphere. Apak et al. [27] have shown that it is possible to reduce the sintering temperature and time through spark plasma sintering, with an SPS soaking temperature of $1300{ }^{\circ} \mathrm{C}$, a pressure of less than $1 \mathrm{kbar}$ and a total sintering duration of just 5 minutes. Sintering of transparent alumina poses challenges due to birefringence of the material, which can make a polycrystalline alumina opaque, even in the absence of porosity, mainly because of the random orientations of grains. The problem with birefringence is partially solved if the grain size is kept below a few hundred nanometers [24, 27], or if the grains are oriented along a single crystallographic axis [26], especially through dopants which cause spin delocalization $[28,29]$. Both of these methods are technologically challenging. However, isotropic structures such as spinel do not pose this challenge [30]. Therefore, industrial scale production of spinel-based transparent ceramics such as aluminum oxynitride $(\mathrm{AlON})$ and magnesium aluminate $\left(\mathrm{MgAl}_{2} \mathrm{O}_{4}\right)$ are widely anticipated. Such ceramics can revolutionize fields requiring abrasion resistant, transparent material at high service temperatures or corrosive media [24]. It is also noteworthy that a technological frontier of transparent polycrystalline ceramics is the field of high-energy solid state lasers [31]. Kong et al. [24] have elegantly reviewed and documented the advancements in the field of sintering transparent polycrystalline ceramics, therefore interested researchers are referred to their book for further information.

Lithium-spinel $\left(\mathrm{LiAl}_{5} \mathrm{O}_{8}\right)$ also known as zeta-alumina [32], has a refractive index of 1.73 (at $588 \mathrm{~nm}$ ). This phase can grow in the surface reaching fractures of sapphire, based on the $\mathrm{Li}_{2} \mathrm{O}-\mathrm{Al}_{2} \mathrm{O}_{3}$ phase diagram, especially at temperatures between 1600 and $1800{ }^{\circ} \mathrm{C}$ [33, 34]. Upon contact of $\mathrm{Li}_{2} \mathrm{O}$ with sapphire, a eutectic fluid is expected at temperatures over $1350{ }^{\circ} \mathrm{C}$, which can facilitate material transport into the fractures. Subsequently, growth of lithium spinel phase begins at the interface [32] and proceeds within fractures. The applied pressure of $1 \mathrm{kbar}$ and temperature of over $1600^{\circ} \mathrm{C}$ during the heat treatment of sapphire are well within the range necessary to sinter monolithic transparent polycrystalline ceramic of lithium spinel. It should also be noted that the reported temperatures for sapphires treated under pressure are debatable, since the temperature distribution in the setup used [19] can be highly dependent on spatial coordinates of a die, as is the case in SPS systems [35], and the actual temperature at the center of the die may be significantly higher. Generally, transparent polycrystalline ceramics do not show devitrification, gas bubbles, striations or glass transition temperatures, which are common in glasses. Once formed, this phase is durable to a wide range of extreme conditions, much like its host material. However, lithium spinel exhibits polymorphic transitions [33], and is therefore capable of inducing unwanted stress in the fractures, which would reduce the final product's average fracture toughness. Recent reports by Peretti et al. [18], regarding sapphires of a potentially lower fracture toughness that are treated under pressure, in addition to their observation of lithium content on the outer peripheries of such gemstones are cause for concern. However, in light of other reports [36] in this regard, further experimental and characterization studies are essential.

There can be many different formulations of transparent polycrystalline ceramics, designed specifically for the purpose of clarity enhancement in corundum. However, let us consider an additional example of aluminum oxynitride (AlON), a spinel structure [37] with a refractive index of 1.79 (at $588 \mathrm{~nm}$ ) [38], hardness of $16.7 \mathrm{GPa}$, fracture toughness of approximately $4 \mathrm{MPa} \mathrm{m}^{1 / 2}$ [39], and thermal expansion coefficient of $5.7 \times 10^{-6} \mathrm{~K}^{-1}$ [40], thereby making it optically and tribologically similar to sapphire. AlON is also thermodynamically compatible with sapphire [41], while being resistant to high temperature, and a wide range of corrosive media. In fact, AlON is often used as an alternative to sapphire for demanding industrial applications [42]. Considering the binary phase diagram [41] of AlN$\mathrm{Al}_{2} \mathrm{O}_{3}$ system, a solubility region exists between approximately 30 to $40 \mathrm{~mol} \% \mathrm{AlN}$, where the AlON phase is stable. The melting temperature of this spinel phase exceeds that of sapphire for most 


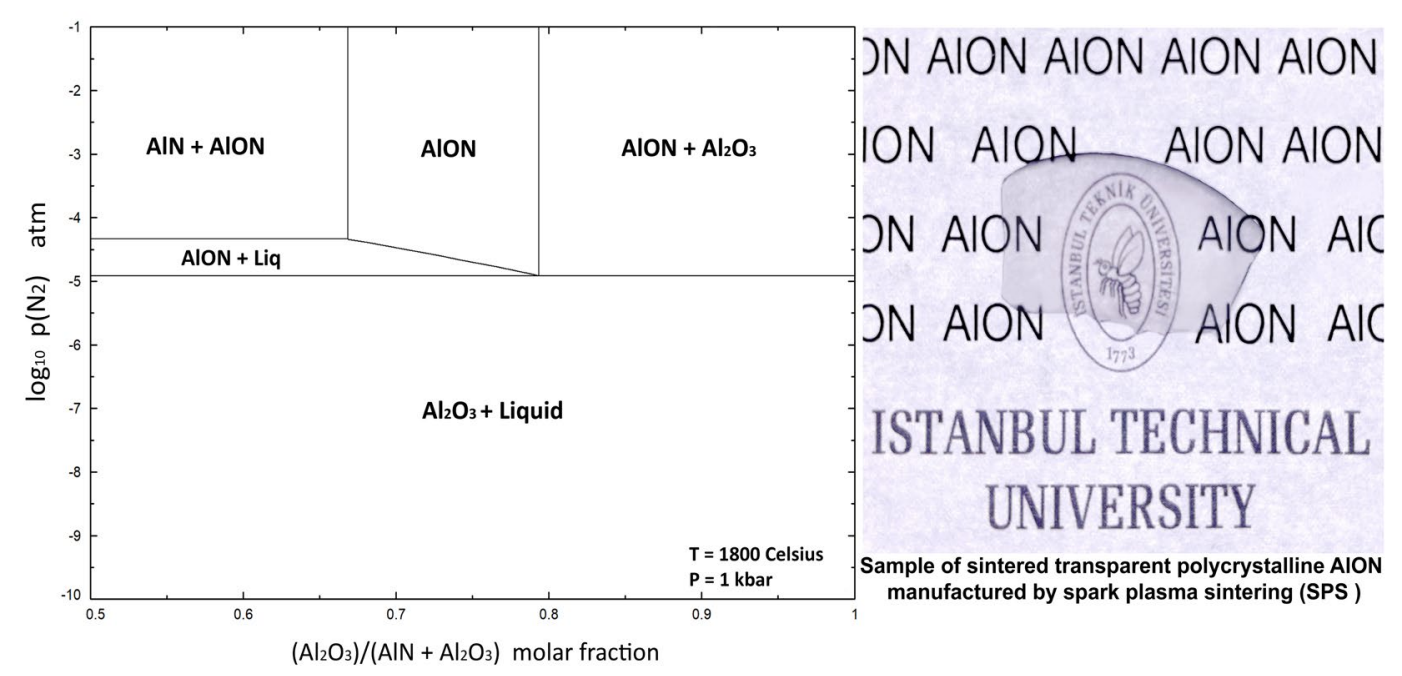

Fig. 2. Left: calculated phase equilibria of $\mathrm{AlN}-\mathrm{Al}_{2} \mathrm{O}_{3}$ system at $1800{ }^{\circ} \mathrm{C}$ and $1 \mathrm{kbar}$ pressure, based on thermochemical database of FactSage [44] for alumina rich composition, as a function of nitrogen partial pressure. Right: an example of transparent AlON as sintered by SPS technology [43].

compositions and therefore, one cannot use this material as a filler in the conventional sense of melting the filler and relying on capillary forces for material transport into fractures, as in the case of glasses. Nevertheless, through transient liquid phase sintering, it becomes possible to transport precursors into the surface reaching fractures by capillary forces. Pressure of approximately $1 \mathrm{kbar}$ and temperatures of over $1700{ }^{\circ} \mathrm{C}$ are sufficient for successful sintering of the AlON phase [39, 43], within the fractures of sapphire. Fig. 2 presents a phase diagram of $\mathrm{AlN}-\mathrm{Al}_{2} \mathrm{O}_{3}$ system at a constant temperature of $1800{ }^{\circ} \mathrm{C}$ and $1 \mathrm{kbar}$ pressure for an alumina rich compositional range, with respect to nitrogen partial pressure, calculated using FactSage [44]. The equilibria clearly shows the possibility of growing AlON within fractures of sapphire at $1800{ }^{\circ} \mathrm{C}$, by regulating partial pressure of gases during treatment. It is also possible to achieve fracture filling of the precursors by increasing the temperature to approximately $1950{ }^{\circ} \mathrm{C}$, where a eutectic fluid will form at the interface of AIN and Sapphire, wetting the fracture surfaces, and facilitating growth of the thermodynamically compatible phase, AlON. Fracture-filled sapphires with aluminum oxynitride used as a filler, would be mechanically durable and optically suitable for the gemstone industry, as the filler material is similar to sapphire. In other words, application of pressure and proper additives during heat treatment processes of corundum, can cause an in-situ sintering of transparent polycrystalline ceramics through liquid phase sintering, thereby rendering gemstone cracks invisible to the unaided eye for all practical purposes.

In any formulation where a transparent polycrystalline ceramic $(\mathrm{X})$ is thermodynamically compatible with alumina, there should exist a two phase region of $\mathrm{X}-\mathrm{Al}_{2} \mathrm{O}_{3}$, similar to that shown in Fig. 2 for an alumina

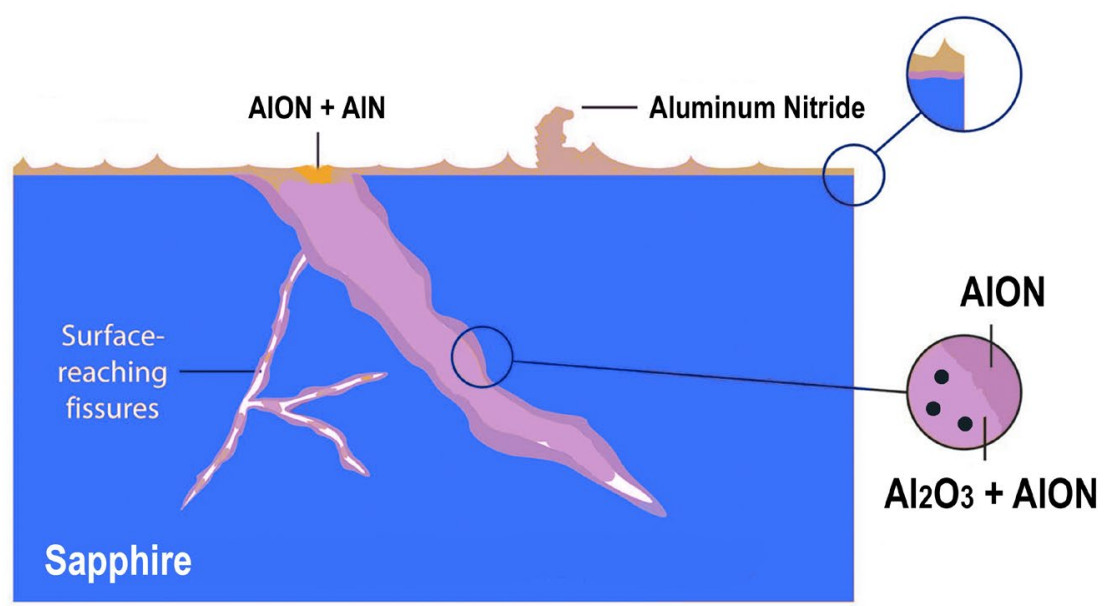

Fig. 3. Schematic representation of a sapphire which is fracture-filled by AlON through an in-situ sintering process. The microstructure of the filler should inevitably contain crystallites of corundum, based on the phase diagram shown in Fig. 2. 
rich compositional range. Such formulations can lead to X-filled fractures where microscopic crystals of corundum should reside. Considering the example of $\mathrm{AlON}$ mentioned earlier, by reducing the partial pressure of nitrogen at $1800{ }^{\circ} \mathrm{C}$, a transient liquid phase emerges which can facilitate transport of the necessary constituents into the fractures. Increasing the nitrogen partial pressure subsequently will result in formation of $\mathrm{AlN}+\mathrm{Al}_{2} \mathrm{O}_{3}$ in solid phase, which will then go through solid state sintering process. Once sufficient densification is achieved, as a result of the applied pressure and temperature, one should expect a transparent AlON ceramic with excess alumina grains remaining segregated. A schematic representation of this process is shown in Fig. 3. In other words, corundum crystallites within such microstructures would be inevitable. The eerie similarity of this hypothetical description, with the recent reports on ghost-fissures that have been observed by Renfro [45], containing crystals of corundum, as identified by Hughes [46, 47], are an additional cause for concern in this regard.

If fillers made of transparent polycrystalline ceramics enter the gemstone market without disclosure, it will be a serious threat to the very foundations of the fine jewelry industry. There are no reports regarding the use of such ceramics in gemstone treatments at this time. In order to avoid a future where such treatments may go undisclosed, gemologists and gemological laboratories alike should be aware, vigilant and cautious regarding the current state of affairs and future advancements on sapphires treated under pressure. The methodology of heat-treating corundum under pressure is still in its infancy, but we anticipate that over the coming years more advanced technologies, such as HIP and SPS will become mainstream in the gemstone treatment industry, and therefore it is only a matter of time until highly engineered transparent polycrystalline ceramic fillers emerge. Therefore, we recommend researchers in gemology to focus part of their efforts on finding methods of non-destructive testing for identification of such filler materials.

It is also important to note the opportunities in this regard. There are no reported fillers available in the gemstone industry, which can compete with the prospects of transparent polycrystalline ceramics at this time. Furthermore, the potentials far exceed sapphire. It is possible to enhance the clarity of other gemstones, such as diamond, in a similar manner. Especially given that high pressure high temperature heat treatments (HPHT) in diamond have a long history [48]. Ceramists are encouraged to consider research in this area, while bearing in mind that disclosure and publication of results, as well as collaboration with gemological institutes for identification of such heat treatments, are essential not just from an ethical perspective, but also for the sustainability and acceptance of successful new formulations.

In conclusion, transparent polycrystalline ceramics have immense potentials in the gem and jewelry industry, and reports on the application of pressure during heat treatment of sapphire make us confident that the gemstone industry is now one-step closer to the next generation of fillers, specifically designed to be optically, chemically and tribologically ideal.

\section{References}

[1] E.R. Dobrovinskaya, L.A. Lytvynov, V. Pishchik, Sapphire material, manufacturing, applications, Springer US, New York, , NY. (2009). DOI:10.1007/978-0-387-85695-7.

[2] R.W. Hughes, W. Manorotkul, E.B. Hughes, Ruby \& sapphire: A gemologist's guide, RWH Publishing. (2017).
[3] L.A. Groat, Geology of gem deposits, Mineralogical Association of Canada. (2007).

[4] E.V. Dubinsky, J. Stone-Sundberg, J.L. Emmett, A quantitative description of the causes of color in corundum, Gems \& Gemology. 56 (2020) 2-28. DOI:10.5741/gems.56.1.2.

[5] S.F. McClure, R.E. Kane, N. Sturman, Gemstone enhancement and its detection in the 2000s, Gems \& Gemology. 46 (2010) 218-240. DOI: 10.5741/gems.46.3.218.

[6] T. Themelis, The Heat Treatment of Ruby \& Sapphire: Experiments \& Observations, 3rd ed., Bangkok, Thailand. (2019).

[7] T. Themelis, Flux-enhanced Rubies \& Sapphires, T. Themelis, Bangkok. (2004).

[8] A.C. Palke, C.M. Breeding, The origin of needle-like rutile inclusions in natural gem corundum: A combined EPMA, LA-ICPMS, and nanoSIMS investigation, American Mineralogist. 102 (2017) 1451-1461. DOI:10.2138/am-2017-5965.

[9] K. Nassau, Heat treating ruby and sapphire: Technical aspects, Gems \& Gemology. 17 (1981) 121-131. DOI:10.5741/gems.17.3.121.

[10]J.L. Emmett, T.R. Douthit, Heat treating the sapphires of Rock Creek, Montana, Gems \& Gemology. 29 (1993) 250-272. DOI: $10.5741 /$ gems.29.4.250.

[11] J.L. Emmett, Fluxes and the Heat Treatment of Ruby and Sapphire, Gems \& Gemology. 35 (1999) 90-92.

[12] S.A. Utlak, T.M. Besmann, Thermodynamic assessment of the $\mathrm{Na} 2 \mathrm{O}-\mathrm{A} 12 \mathrm{O} 3-\mathrm{SiO} 2-\mathrm{B} 2 \mathrm{O} 3$ pseudo-binary and -ternary systems, The Journal of Chemical Thermodynamics. 130 (2019) 251-268. https://doi.org/10.1016/j.jct.2018.09.001.

[13] M. Mansoor, M. Mansoor, M. Mansoor, Z. Er, The Potentials of Lanthanum Borates in Heat Treatments of Corundum, Int. Conf. Advanced. Mater. Sci.\& Eng. HiTech.and Device Appl. (2020).

[14] J.I. Koivula, Induced fingerprints, Gems \& Gemology. 19 (1983) 220-227. DOI:10.5741/gems.19.4.220.

[15] S.F. McClure, C.P. Smith, W. Wang, M. Hall, Identification and durability of lead glass-filled rubies, Gems \& Gemology. 42 (2006) 22-36. DOI: 10.5741/gems.42.1.22.

[16] K. Nassau, Gemstone enhancement: History, science and state of the art, Butterworth-Heinemann, Oxford. (1994).

[17] H.M. Choi, S.K. Kim, Y.C. Kim, New treated blue sapphire by HPHT apparatus, Proceedings of the 4th International Gem and Jewelry Conference. GIT. (2014).

[18] A. Peretti, M. Musa, W. Bieri, E. Cleveland, I. Ahamed, M. Alessandri, et al., Identification and characteristics of PHT ('HPHT') - treated sapphires - An update of the GRS research progress, GRS. (2018).

[19] CGL Central Gem Lab, CISGEM, DSEF German Gem Lab, GIA Gemmological Institute of America, GIT Gem and Jewelry Institute of Thailand, Gübelin Gem Lab, SSEF Swiss Gemmological Institute, Lotus Gemology, ICA Lab, Dunaigre Consulting, GJEPC-GTL, \& Hanmi Lab, Sapphire Heated with Pressure (Slides), The Gem \& Jewelry Institute of Thailand. (2019).

[20] H.-S. Kim, S. Roberts, Brittle-Ductile transition and DISLOCATION mobility in Sapphire, Journal of the American Ceramic Society. 77 (1994) 3099-3104. https://doi.org/10.1111/j.1151-2916.1994.tb04555.x.

[21] M.L. Kronberg, Plastic deformation of single crystals of sapphire: Basal slip and twinning, Acta Metallurgica. 5 (1957) 507-524. https://doi.org/10.1016/0001-6160(57)90090-1.

[22] K.P. Lagerlof, A.H. Heuer, J. Castaing, J.P. Riviere, T.E. Mitchell, Slip and twinning in sapphire (alpha-al2o3), Journal of the American Ceramic Society. 77 (1994) 385-397. https://doi.org/10.1080/01418619808241934.

[23] K.P. Lagerlof, B.J. Pletka, T.E. Mitchell, A.H. Heuer, Deformation and diffusion in sapphire ( $\alpha$-al2o3), Radiation Effects. 74 (1983) 87 107. https://doi.org/10.1080/00337578308218402.

[24] L.B. Kong, Y.Z. Huang, W. Que, T.S. Zhang, S. Li, J. Zhang, Z.L. Dong, D.Y. Tang, Transparent ceramics, Springer, Cham. (2015). DOI: 10.1007/978-3-319-18956-7. 
[25] Z. Xiao, S. Yu, Y. Li, S. Ruan, L.B. Kong, Q. Huang, et al., Materials development and potential applications of Transparent Ceramics: A Review, Materials Science and Engineering: R: Reports. 139 (2020) 100518. https://doi.org/10.1016/j.mser.2019.100518.

[26] X. Mao, S. Wang, S. Shimai, J. Guo, Transparent polycrystalline alumina ceramics with orientated optical axes, Journal of the American Ceramic Society. 91 (2008) 3431-3433. https://doi.org/10.1111/j.1551-2916.2008.02611.x.

[27] B. Apak, G. Göller, Y. Onüralp, F.Ç. Şahin, The effects of codoping $\mathrm{Y} 2 \mathrm{O} 3$ on $\mathrm{MgO}$ doped spark plasma sintered $\mathrm{Al} 2 \mathrm{O} 3$, Advances in Science and Technology. 63 (2010) 74-78. https://doi.org/10.4028/www.scientific.net/AST.63.74.

[28] M. Mansoor, M. Mansoor, M. Mansoor, Z. Er, F. Ç. Şahin, Ab-initio study of paramagnetic defects in $\mathrm{Mn}$ and $\mathrm{Cr}$ doped transparent polycrystalline A12O3 ceramics, Synthesis and Sintering. 1 (2021). https://doi.org/10.53063/synsint.2021.1340.

[29] E.C. Nykwest, S.P. Alpay, Towards magnetic alumina: Uncovering the roles of transition metal doping and electron hybridization in spin delocalization, Journal of Physics: Condensed Matter. 31 (2019) 245801. DOI:10.1088/1361-648x/ab0fe4.

[30] S.F. Wang, J. Zhang, D.W. Luo, F. Gu, D.Y. Tang, Z.L. Dong, et al., Transparent ceramics: Processing, materials and applications, Progress in Solid State Chemistry. 41 (2013) 20-54. https://doi.org/10.1016/j.progsolidstchem.2012.12.002.

[31] J. Sanghera, S. Bayya, G. Villalobos, W. Kim, J. Frantz, B. Shaw, et al., Transparent ceramics for high-energy laser systems, Optical Materials. 33 (2011) 511-518. https://doi.org/10.1016/j.optmat.2010.10.038.

[32] H.B. Barlett, Occurrence and properties of crystalline alumina in silicate melts, Journal of the American Ceramic Society. 15 (1932) 361-361. https://doi.org/10.1111/j.1151-2916.1932.tb13944.x.

[33] B. Konar, I.-H. Jung, A coupled phase diagram experimental study and thermodynamic optimization of the LI2O-cao-al2o3 and LI2OCao-SIO2 systems, and prediction of the phase diagrams of the LI2O-cao-AL2O3-sio2 system, Journal of the European Ceramic Society. 40 (2020) 2185-2199. https://doi.org/10.1016/j.jeurceramsoc.2019.12.043.

[34] N.S. Kulkarni, T.M. Besmann, K.E. Spear, Thermodynamic optimization of Lithia-Alumina, Journal of the American Ceramic Society. 91 (2008) 4074-4083. https://doi.org/10.1111/j.15512916.2008.02753.x.

[35] M. Sakkaki, F. Sadegh Moghanlou, M. Vajdi, M. Shahedi Asl, M. Mohammadi, M. Shokouhimehr, Numerical simulation of heat transfer during Spark Plasma Sintering of zirconium diboride,
Ceramics International. 46 (2020) 4998-5007.

https://doi.org/10.1016/j.ceramint.2019.10.240.

[36] R.W. Hughes, Pressure Heated Sapphire • Squeezing Sapphire • Corundums treated with high temperatures and low pressure $(\mathrm{HT}+\mathrm{P})$, LotusGemology. (2019).

[37] J.W. McCauley, A simple model for aluminum oxynitride spinels, Journal of the American Ceramic Society. 61 (1978) 372-373. https://doi.org/10.1111/j.1151-2916.1978.tb09336.x.

[38] Batsanov S. S., E.D. Ruchkin, I.A. Poroshina, Refractive indices of Solids, Springer, Singapore, (2016). DOI: 10.1007/978-981-100797-2.

[39] F.C. Sahin, H.E. Kanbur, B. Apak, Preparation of alon ceramics via reactive spark plasma sintering, Journal of the European Ceramic Society. 32 (2012) 925-929. https://doi.org/10.1016/j.jeurceramsoc.2011.10.043.

[40] M. Bass, Handbook of Optics, 2nd ed., McGraw-Hill, New York etc. (1995).

[41] A. Maghsoudipour, F. Moztarzadeh, M. Saremi, J.G. Heinrich, Oxidation behavior of ALN-A12O3 Composites, Ceramics International. 30 (2004) 773-783.

https://doi.org/10.1016/j.ceramint.2003.10.004.

[42] D. Clay, D. Poslusny, M. Flinders, S.D. Jacobs, R.A. Cutler, Effect of LIAL5O8 additions on the sintering and optical transparency of lialon, Journal of the European Ceramic Society. 26 (2006) 13511362. https://doi.org/10.1016/j.jeurceramsoc.2005.01.056.

[43] H.E. Kanbur, Production and Characterization of Alon Ceramics by Reactive Spark Plasma Sintering Method, Master's thesis. (2012). http://hdl.handle.net/11527/9175.

[44]C.W. Bale, E. Bélisle, P. Chartrand, S.A. Decterov, G. Eriksson, A.E. Gheribi, et al., FactSage thermochemical software and databases, 2010-2016, Calphad. 54 (2016) 35-53. https://doi.org/10.1016/j.calphad.2016.05.002.

[45] N. Renfro, Microscopic Observations of Blue Sapphires Treated with Heat and Pressure, Gems \& Gemology. 54 (2018) 458.

[46] R.W. Hughes, A "ghost" fissure in a Sri Lankan sapphire treated with high-temperature heating plus pressure $(\mathrm{HT}+\mathrm{P})$ - Hyperion • Inclusion Search Engine, LotusGemology. Image Number: A-0034780-1. (2019).

[47] E.B. Hughes, A "ghost" fissure in a Sri Lankan sapphire treated with high-temperature heating plus pressure $(\mathrm{HT}+\mathrm{P})$ - Hyperion • Inclusion Search Engine, LotusGemology. Image Number: A-0031024-2. (2018).

[48] I.A. Dobrinets, V.G. Vins, A.M. Zaitsev, HPHT-Treated Diamonds, Springer, Berlin. (2013) . DOI:10.1007/978-3-642-37490-6. 